\title{
Conformational Behavior of Dimethyl 5-Methyl-1H,3H-pyrrolo[1,2-c][1,3]thiazole-6,7-dicarboxylate 2,2-Dioxide Isolated in Low-Temperature Matrixes
}

\author{
A. Kaczor, ${ }^{\dagger}, *$ T. M. V. D. Pinho e Melo,${ }^{\dagger}$ M. I. L. Soares, ${ }^{\dagger}$ and R. Fausto ${ }^{*, \dagger}$ \\ Department of Chemistry, University of Coimbra, P-3004-535 Coimbra, Portugal, and Faculty of Chemistry, \\ Jagiellonian University, Ingardena 3, 30-060 Krakow, Poland
}

Received: February 6, 2006; In Final Form: March 24, 2006

\begin{abstract}
The structure of dimethyl 5-methyl-1H,3H-pyrrolo[1,2-c][1,3]thiazole-6,7-dicarboxylate 2,2-dioxide (PTD) was investigated in low-temperature noble gas matrixes ( $\mathrm{Ar}, \mathrm{Kr}, \mathrm{Xe}$ ), amorphous solid, and the crystalline state by infrared spectroscopy and computational methods. The geometry of PTD conformers is defined by the orientation of two methyl ester groups, which may adopt pseudo-trans or pseudo-cis positions in relation to the pyrrolo-thiazole system. For both methyl ester groups, the latter arrangement was predicted by the calculations to be energetically the most favorable in the isolated molecule. The envelope form of the thiazolidine ring is present in all conformers, with the sulfur atom placed in the apex position, while the pyrrole ring is almost planar. Three types of conformers differing in the orientation of the methyl ester groups relative to the pyrrolo-thiazole system (cis/cis, trans/cis, cis/trans) were identified in the matrixes. The cis/ cis forms were found to be the most stable ones in both gaseous state and argon matrixes. On the other hand, the more polar trans/cis forms were found to be stabilized in the more polarizable krypton and xenon matrixes as well as in the neat amorphous and crystalline phases. On the basis of annealing experiments, performed in argon and xenon matrixes up to 35 and $68 \mathrm{~K}$, respectively, conformational changes preceding the aggregation of the compound are suggested.
\end{abstract}

\section{Introduction}

Pyrrolo[1,2-c]thiazole derivatives (cf. Figure 1) are compounds of considerable importance, as some representatives show interesting biological activities. In fact, it is known that some 5-substituted-6,7-bis(hydroxymethyl)pyrrolo[1,2-c]thiazoles, including sulfone derivatives, have antitumoral activity. In particular, compound $\mathbf{1}$ is one example of a compound with antileukemic activity. It is also known that some pyrrolo[1,2c]thiazole derivatives with the general structure $\mathbf{2}$ show antiallergic and antiinflammatory activity. Compounds $\mathbf{3}$ and $\mathbf{4}$ have PAF receptor antagonist properties. PAF (platelet activating factor) is a highly potent phospholipid mediator of inflammation, implicated as an important mediator in a number of lifethreatening conditions, including septic shock and asthma. ${ }^{1-4}$

Pyrrolo[1,2-c]thiazole derivatives have also proven to be useful building blocks in organic synthesis. Of particular interest is the reactivity of $1 H, 3 H$-pyrrolo[1,2-c]thiazole-2,2-dioxides and $1 H, 3 H$-pyrrolo[1,2-c] thiazole-2-oxides as precursors of new reactive intermediates such as azafulvenium methides, thiocarbonyl ylides and azomethine ylides, which in turn allow the construction of further new heterocyclic systems. ${ }^{5-8}$

Getting further knowledge on the chemistry of pyrrolo[1,2$c$ thiazoles is then a relevant research goal. In this paper, we describe the conformational behavior of dimethyl 5-methyl1H,3H-pyrrolo[1,2-c] thiazole-6,7-dicarboxylate-2,2-dioxide (PTD) in argon, krypton, and xenon matrixes and investigate its lowtemperature neat amorphous and crystalline phases and aggregation process.

* Corresponding author. E-mail: rfausto@ci.uc.pt.

$\dagger$ Department of Chemistry, University of Coimbra

$\stackrel{*}{*}$ Faculty of Chemistry, Jagiellonian University.

\section{Experimental Section}

PTD (8) was prepared from L-cysteine by known synthetic procedures $^{7,9}$ (cf. Scheme 1). Heating a solution of 1,3thiazolidine-4-carboxylic acid (5) in acetic anhydride allows the in situ generation of the bicyclic mesoionic ring system $\mathbf{6}$. This latter then reacts with dimethyl acetylenedicarboxylate to give the corresponding 1,3-dipolar cycloadduct, 5-methyl- $1 \mathrm{H}, 3 \mathrm{H}$ pyrrolo[1,2-c]thiazole (7). Oxidation of the heterocycle 7 with MCPBA ( $m$-chloroperoxybenzoic acid) gives the sulfone $\mathbf{8}$ in good yield.

FT-IR spectra were recorded in the $400-4000 \mathrm{~cm}^{-1}$ range using a Mattson Infinity 60AR series FT-IR spectrometer, with 0.5 and $1 \mathrm{~cm}^{-1}$ resolution for the matrix and amorphous/ crystalline state, respectively.

To obtain the matrix spectra, PTD was sublimated using a minifurnace placed inside the cryostat and co-deposited with the cryogenic gas (argon N60, krypton N48, or xenon N45; all obtained from Air Liquide) onto the cooled CsI optical substrate of the cryostat. The spectrum of the neat amorphous solid of PTD was obtained using a similar procedure, but without applying the isolant cryogenic gas. PTD sublimation temperatures used were around $423 \mathrm{~K}$ in the case of the experiments in $\mathrm{Ar}$ and neat amorphous solid. For $\mathrm{Kr}$ and $\mathrm{Xe}$ matrixes, a different arrangement of the mini-furnace was used, which allowed reduction of the sublimation temperature to 388-403 $\mathrm{K}$. The temperature of the optical substrate (ca. $11 \mathrm{~K}$, in the experiments in Ar and $\mathrm{Kr}$ matrixes and neat solid PTD, and 20 $\mathrm{K}$, in the experiments in Xe matrixes) was obtained using an APD Cryogenics closed-cycle helium refrigeration system with a DE-202A expander. In all experiments, the temperature was measured directly at the sample holder by a silicon diode 


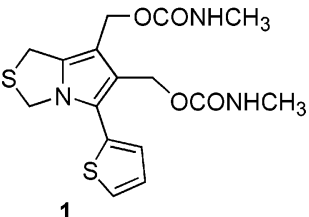

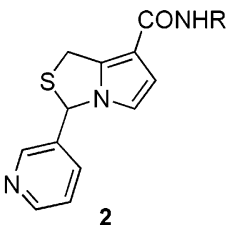

$3 R^{1}={ }_{N}^{N}$

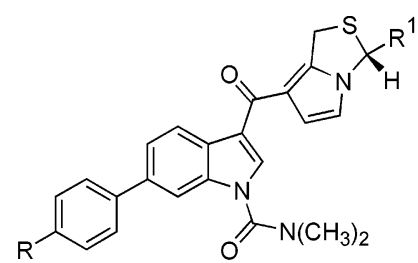

$4 \mathrm{R}^{1}=\overbrace{\mathrm{CH}_{3}}^{\mathrm{O}}$

Figure 1. Pyrrolo[1,2-c]thiazole derivatives.

\section{SCHEME 1. Synthesis of PTD}

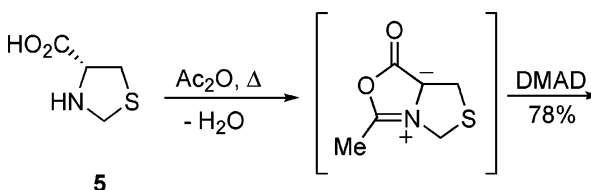

temperature sensor, connected to a digital controller (Scientific Instruments, model 9650-1), with an accuracy of $0.1 \mathrm{~K}$.

Annealing of the matrixes was performed by increasing the temperature gradually up to 35,45 , and $68 \mathrm{~K}$, for $\mathrm{Ar}, \mathrm{Kr}$, and $\mathrm{Xe}$ matrixes, respectively. The spectra of the annealed matrixes were recorded without subsequent cooling cycle.

Annealing of the amorphous solid layer was done up to 298 $\mathrm{K}$, when the amorphous-to-crystal phase transition was observed. Subsequently, a cooling-heating cycle was applied to the obtained crystalline sample within the 10-298 K temperature range. IR spectra were recorded in steps of $25 \mathrm{~K}$.

\section{Computational Methods}

To examine the conformational space of PTD, a systematic independent variation of the two relevant torsion angles $\left(\mathrm{C}_{2} \mathrm{C}_{1} \mathrm{C}_{19} \mathrm{O}_{21}\right.$ and $\left.\mathrm{C}_{5} \mathrm{C}_{4} \mathrm{C}_{20} \mathrm{O}_{23}\right)$, from $0^{\circ}$ to $360^{\circ}$, with increment of $90^{\circ}$, was undertaken. Optimization of the input structures at the B3LYP level ${ }^{10,11}$ with the $6-31+\mathrm{G}(\mathrm{d})$ basis set brought eight different minimum energy structures, all of them having an equivalent-by-symmetry mirror image. These structures were then reoptimized and vibrational frequencies calculated at the B3LYP/6-311++G(d,p) level. Unique structures of $C_{s}$ symmetry were recognized as third-order transition states.

According to previous analyses, ${ }^{12-14}$ the vibrational frequencies associated with $\mathrm{S}=\mathrm{O}$ bond stretches are usually underestimated when calculated both at the DFT (B3LYP) level with the split-valence triple- $\xi 6-311++\mathrm{G}(\mathrm{d}, \mathrm{p})$ basis set and at the MP2 level with the split-valence double- $\xi 6-31++\mathrm{G}(\mathrm{d}, \mathrm{p})$ basis set. This result does not follow the usual trend, which is a general overestimation of vibrational frequencies by this type of calculations. Accurate reproduction of frequencies associated with the $\mathrm{S}=\mathrm{O}$ bond stretching modes could only be obtained with the B3LYP method when the split-valence quadruple- $\xi$ basis set aug-cc-pVQZ was used; this has been achieved, for instance, for dimethyl sulfate and dimethyl sulfite. ${ }^{12,13}$ However, the size of the PTD molecule excludes any possibility of undertaking the calculations at this level. Therefore, the vibrational frequencies previously calculated at the B3LYP/augcc-pVQZ level for dimethyl sulfate ${ }^{12}$ were compared to those obtained for the same compound using the affordable 6-311++G$(d, p)$ basis set, to obtain the proper scaling factors for the $\mathrm{S}=\mathrm{O}$ stretching frequencies calculated using the latter basis set for

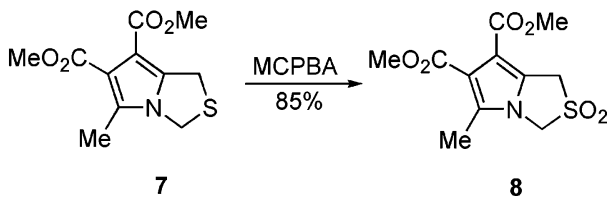

TABLE 1: Comparison of the B3LYP S=O Stretching Vibrational Frequencies (in $\mathrm{cm}^{-1}$ ) of Dimethyl Sulfate Obtained Using the 6-311++G(d,p) and aug-cc-pVQZ Basis Sets

\begin{tabular}{|c|c|c|c|}
\hline \multirow[b]{2}{*}{ assignment } & \multicolumn{2}{|c|}{ B3LYP } & \multirow{2}{*}{$\begin{array}{l}\text { B3LYP/6-311++G(d,p) to } \\
\text { B3LYP/aug-cc-pVQZ ratio }\end{array}$} \\
\hline & $6-311++\mathrm{G}(\mathrm{d}, \mathrm{p})$ & aug-cc-pVQZ ${ }^{12}$ & \\
\hline$v(\mathrm{~S}$ & 1372.8 & 14 & 0 \\
\hline$v(\mathrm{~S}=\mathrm{O})$ & 1151.8 & 1197.9 & 1.040 \\
\hline
\end{tabular}

PTD. Table 1 shows the frequencies of the $\mathrm{S}=\mathrm{O}$ stretching vibrations calculated using the two basis sets. The B3LYP/6$311++\mathrm{G}(\mathrm{d}, \mathrm{p})$ to $\mathrm{B} 3 \mathrm{LYP} / \mathrm{aug}-\mathrm{cc}-\mathrm{pVQZ}$ frequency ratios are 1.027 and 1.040 for the antisymmetric and symmetric $\mathrm{S}=\mathrm{O}$ stretching vibrations, respectively, with the mean value being equal to 1.035. This mean value was then accepted in this study as scaling factor for the B3LYP/6-311++G(d,p) $\mathrm{S}=\mathrm{O}$ stretching frequencies calculated for PTD. The scaling factor 0.99 was applied for all other frequencies.

Additionally, the thermochemical properties were computed for all stable conformers of PTD, to obtain their relative abundance at the sublimation temperatures ( 388 and $423 \mathrm{~K}$ ). The latter was calculated using the $\Delta G^{\circ}=R T \ln K_{\mathrm{c}}$ equation, where $\Delta G^{\circ}$ is the standard Gibbs free energy relative to the most stable conformer, calculated at the B3LYP/6-311++G(d,p) level, and $K_{\mathrm{c}}$ is the ratio of the concentrations of a pair of conformers.

Finally, the synchronous transit-guided quasi-Newton (STQNQST3) method ${ }^{15}$ was used to estimate the barriers for the conformational interconversions between pairs of conformers differing by internal rotation around one bond.

All calculations were done with the Gaussian 03 set of programs. ${ }^{16}$

Potential energy distributions (PED) calculations and normal coordinate analyses were computed in terms of natural internal coordinates ${ }^{17}$ with the Gar2ped program. ${ }^{18}$

\section{Results and Discussion}

4.1. Geometries and Energies. The adopted numbering scheme for PTD is presented in Figure 2. Optimized geometries of the conformers calculated at the B3LYP/6-311++G(d,p) level of theory are given in Figure 3, along with the dihedral angles defining the structures. All conformers have symmetry 


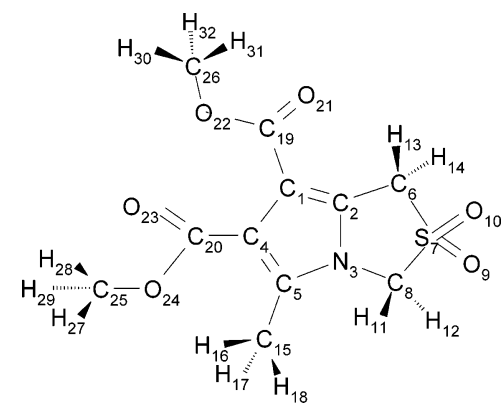

Figure 2. Adopted numbering scheme for the PTD molecule.
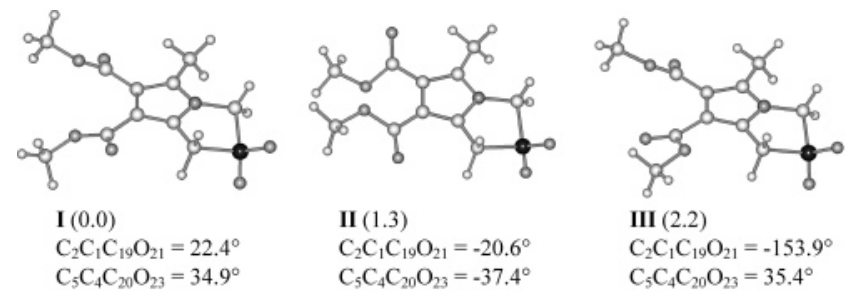

II (1.3)

$\mathrm{C}_{2} \mathrm{C}_{1} \mathrm{C}_{19} \mathrm{O}_{21}=-20.6^{\circ}$

$\mathrm{C}_{5} \mathrm{C}_{4} \mathrm{C}_{20} \mathrm{O}_{23}=-37.4^{\circ}$

III (2.2)

$\mathrm{C}_{2} \mathrm{C}_{1} \mathrm{C}_{19} \mathrm{O}_{21}=-153.9^{\circ}$

$\mathrm{C}_{5} \mathrm{C}_{4} \mathrm{C}_{20} \mathrm{O}_{23}=35.4^{\circ}$
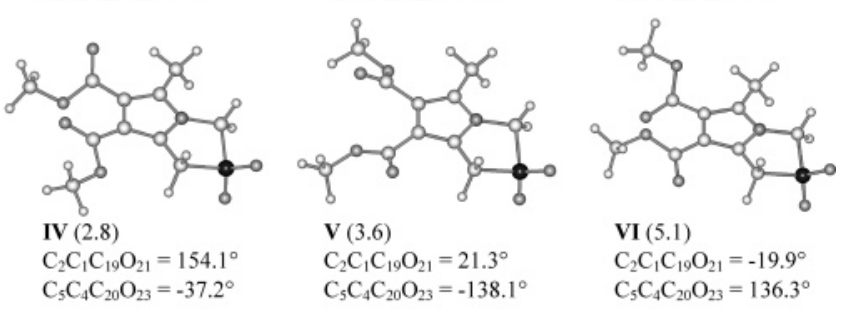

$\mathrm{C}_{2} \mathrm{C}_{1} \mathrm{C}_{19} \mathrm{O}_{21}=21.3^{\circ}$

$\mathrm{C}_{5} \mathrm{C}_{4} \mathrm{C}_{20} \mathrm{O}_{23}=-138.1^{\circ}$

VI (5.1)

$\mathrm{C}_{2} \mathrm{C}_{1} \mathrm{C}_{19} \mathrm{O}_{21}=-19.9^{\circ}$

$\mathrm{C}_{5} \mathrm{C}_{4} \mathrm{C}_{20} \mathrm{O}_{23}=136.3^{\circ}$
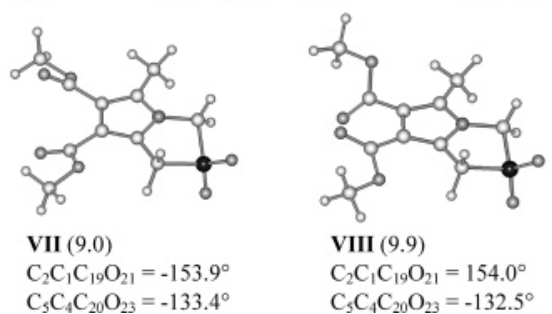

Figure 3. Optimized geometries of PTD conformers [B3LYP/6$311++\mathrm{G}(\mathrm{d}, \mathrm{p})]$. The values of zero-point corrected energy (in kJ mol${ }^{-1}$ ) relative to conformer $\mathbf{I}$ are given in parentheses.

related equivalent forms, which can be obtained from the first ones by applying the inversion symmetry operation. In the chosen set, the conformers have the same arrangement of the thiazolidine ring in respect to the pyrrole moiety (in all forms the $\mathrm{C}_{2} \mathrm{C}_{6} \mathrm{~S}_{7} \mathrm{C}_{8}$ dihedral angle has a positive value, while both the $\mathrm{N}_{3} \mathrm{C}_{2} \mathrm{C}_{6} \mathrm{~S}_{7}$ and $\mathrm{C}_{6} \mathrm{~S}_{7} \mathrm{C}_{8} \mathrm{~N}_{3}$ dihedral angles have negative signs). The zero-point corrected energies, dipole moments, standard Gibbs free energies and abundances of the conformers, calculated at the two sublimation temperatures used in the experiments (388 and $423 \mathrm{~K}$ ), are given in Table 2. Table 1S, provided as Supporting Information, presents the complete set of geometrical parameters for the calculated conformers of PTD.

The $\mathrm{C}_{2} \mathrm{C}_{1} \mathrm{C}_{19} \mathrm{O}_{21}$ and $\mathrm{C}_{5} \mathrm{C}_{4} \mathrm{C}_{20} \mathrm{O}_{23}$ (or alternatively $\mathrm{C}_{2} \mathrm{C}_{1} \mathrm{C}_{19} \mathrm{O}_{22}$ and $\mathrm{C}_{5} \mathrm{C}_{4} \mathrm{C}_{20} \mathrm{O}_{24}$ ) torsion angles define the differences between the PTD conformers, while the other geometrical parameters are quite conserved. The envelope form of the thiazolidine ring is predicted for all conformers, with an almost planar $\mathrm{C}_{6} \mathrm{C}_{2} \mathrm{~N}_{3} \mathrm{C}_{8}$ torsion angle $\left(-0.9\right.$ to $\left.-1.1^{\circ}\right)$ and the sulfur atom placed in the apex position. The twisted conformation of the ring was not considered due to the fact that it is expected to possess a significantly higher energy; for unsubstituted pyrrolidine, the twisted conformation was shown [MP2/6-31G(d,p)] to be ca. $22 \mathrm{~kJ} \mathrm{~mol}^{-1}$ less stable than the envelope form. ${ }^{19}$ In all conformers, the angle between the $\mathrm{C}_{6} \mathrm{~S}_{7} \mathrm{C}_{8}$ and $\mathrm{N}_{3} \mathrm{C}_{8} \mathrm{~S}_{7}$ planes is in the $19.0-21.8^{\circ}$ range.
TABLE 2: Relative Zero-Point Corrected Energies $\left(\Delta E^{\circ}\right)$, Dipole Moments $(\mu)$, Relative Standard Gibbs Free Energies $\left(\Delta G^{\circ}\right)$ and Abundances $(A)$ of PTD Conformers

\begin{tabular}{|c|c|c|c|c|c|c|}
\hline \multirow[b]{2}{*}{ conformer $^{a}$} & \multirow[b]{2}{*}{$\begin{array}{c}\Delta E^{\circ} \\
\left(\mathrm{kJ} \mathrm{mol}^{-1}\right)^{b}\end{array}$} & \multirow[b]{2}{*}{$\begin{array}{l}\mu \\
\text { (D) }\end{array}$} & \multicolumn{2}{|c|}{$\Delta G^{\circ}\left(\mathrm{kJ} \mathrm{mol}^{-1}\right)$} & \multicolumn{2}{|c|}{$A(\%)$} \\
\hline & & & $\begin{array}{c}388.15 \\
\mathrm{~K}^{c}\end{array}$ & $\begin{array}{c}423.15 \\
\mathrm{~K}^{c}\end{array}$ & $\begin{array}{c}388.15 \\
\mathrm{~K}\end{array}$ & $\begin{array}{c}423.15 \\
\mathrm{~K}\end{array}$ \\
\hline I & 0.0 & 4.3 & 0.0 & 0.0 & 30 & 24 \\
\hline II & 1.3 & 4.0 & 0.3 & 0.3 & 26 & 22 \\
\hline III & 2.2 & 3.4 & 1.7 & 1.7 & 15 & 15 \\
\hline IV & 2.8 & 0.7 & 2.5 & 2.4 & 11 & 12 \\
\hline V & 3.6 & 5.2 & 2.8 & 2.7 & 9 & 11 \\
\hline VI & 5.1 & 6.2 & 3.5 & 3.4 & 7 & 9 \\
\hline VII & 9.0 & 2.9 & 7.0 & 6.7 & 2 & 4 \\
\hline VIII & 9.9 & 3.4 & 7.7 & 7.9 & 1 & 3 \\
\hline
\end{tabular}

${ }^{a} \mathrm{~B} 3 \mathrm{LYP} / 6-311++\mathrm{G}(\mathrm{d}, \mathrm{p})$; all structures have $C_{1}$ symmetry. ${ }^{b} E^{\circ}=$ -1331.282906 hartree for conformer I. ${ }^{c} G^{\circ}=-1331.354312$ hartree and $G^{\circ}=-1331.363815$ hartree for conformer $\mathbf{I}$ at 388.15 and 423.15 $\mathrm{K}$, respectively.

The differences in the bond lengths calculated for the various conformers do not exceed $0.005 \AA$, with a slightly larger deviation noticed only in the case of $\mathrm{C}-\mathrm{O}$ bond lengths $(\mathrm{C}=$ 19 and $20, \mathrm{O}=21,22,23$, and 24; see atom numbering in Figure 2), which attain the maximum observed difference value of $0.023 \AA$. The calculated values for angles are also quite conserved, with the maximum deviation being ca. $6^{\circ}$ for both bond and dihedral angles, if the absolute values in the case of the latter are considered.

The $\mathrm{C}_{2} \mathrm{C}_{1} \mathrm{C}_{19} \mathrm{O}_{21}$ and $\mathrm{C}_{5} \mathrm{C}_{4} \mathrm{C}_{20} \mathrm{O}_{23}$ dihedrals may adopt two different orientations, close to cis and trans positions, with mean absolute values of $21.1^{\circ} / 154.0^{\circ}$ for $\mathrm{C}_{2} \mathrm{C}_{1} \mathrm{C}_{19} \mathrm{O}_{21}$ and $36.2^{\circ} / 135.1^{\circ}$ for $\mathrm{C}_{5} \mathrm{C}_{4} \mathrm{C}_{20} \mathrm{O}_{23}$. In the gas phase, the arrangement with simultaneous pseudo-cis conformation of these two dihedral angles is the most favorable. It is adopted in the two most stable conformers, I and II. These two conformers differ in energy $(\Delta E)$ only by $1.3 \mathrm{~kJ} \mathrm{~mol}^{-1}$ (with zero point energy correction included). Forms with one of the dihedral angles in the pseudotrans arrangement are significantly less stable, particularly when the $\mathrm{C}_{5} \mathrm{C}_{4} \mathrm{C}_{20} \mathrm{O}_{23}$ dihedral adopts this conformation $(\Delta E=2.2$, 2.8, 3.6, and $5.1 \mathrm{~kJ} \mathrm{~mol}^{-1}$ for III, IV, $\mathbf{V}$, and VI respectively). Conformers VII and VIII, with both dihedral angles in the pseudo-trans conformation, are destabilized by $9.0 \mathrm{~kJ} \mathrm{~mol}^{-1}$ or more, relative to $\mathbf{I}$.

The relative energy of the different conformers is mainly controlled by the repulsions between the oxygen atoms, which are stronger for the carbonyl oxygen atoms than for the methoxyl oxygen atoms bearing smaller negative charge. This is illustrated by the increase in the distance between the closest oxygen atoms from ca. $2.85 \AA$ in conformers I and II, through ca. 2.89-2.90 $\AA$ in III, IV, V, and VI, to about $3.02 \AA$ in VII and VIII. The calculations predict that the six lowest energy conformers of PTD should have abundances higher than 9 and $7 \%$ in the gaseous phase at 388 and $423 \mathrm{~K}$, respectively. The joint abundance of conformers VII and VIII should not exceed $2 \%$ at $388 \mathrm{~K}$ and $4 \%$ at $423 \mathrm{~K}$.

4.2. Spectra of Matrix-Isolated PTD. The fingerprint regions of the spectra of PTD isolated in solid argon and xenon are presented in Figure 4. This figure also shows the spectrum resulting from adding the theoretically predicted IR spectra of the PTD conformers scaled by their calculated abundances at $423 \mathrm{~K}$ (the spectrum corresponding to $388 \mathrm{~K}$ is qualitatively similar to this one due to similar conformer abundances at both temperatures and it is not shown). 


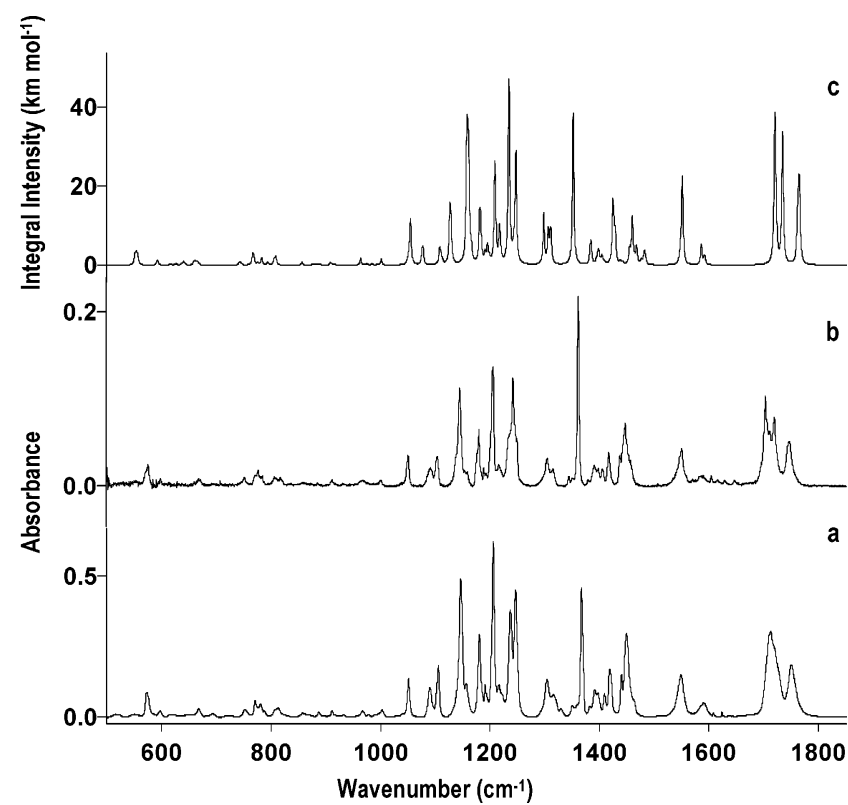

Figure 4. Comparison of the FT-IR spectra of PTD isolated in argon (a) and xenon (b) matrix with the spectrum resulting from the sum of the calculated [B3LYP/6-311++G(d,p)] spectra of conformers I-VI (c), in the $500-1850 \mathrm{~cm}^{-1}$ range. In the calculated spectrum, intensities were weighted by the estimated relative abundances at $423 \mathrm{~K}$; frequencies were scaled as described in the Computational Methods section.

Both the conformational flexibility as well as the size of the PTD molecule implicates broad and superimposed bands in the experimental spectra. In addition, the predicted frequencies for the pairs of conformers differing by the signs of both $\mathrm{C}_{2} \mathrm{C}_{1} \mathrm{C}_{19} \mathrm{O}_{21}$ and $\mathrm{C}_{5} \mathrm{C}_{4} \mathrm{C}_{20} \mathrm{O}_{23}$ dihedrals (e.g., I/II, III/IV, V/VI, and VII/ VIII) are practically coincident. Therefore, these pairs of conformers are particularly difficult to differentiate based on experiment. Hence, the proposed assignment of the spectra (see Tables $2 \mathrm{~S}$ and $3 \mathrm{~S}$ in the Supporting Information) should be treated as tentative. Nevertheless, the presence of three different types of conformations: cis/cis (I and II), cis/trans (III and IV), and trans/cis ( $\mathbf{V}$ and $\mathbf{V I}$ ) is proven on the basis of experimental data, as shown in detail below. On the other hand, it is not possible to identify experimentally the highest energy conformers, VII and VIII, due to their low abundance. Because of the possible influence of a matrix environment on the relative abundance of conformers during the deposition process, computed abundance values should be treated as semiquantitative, rather than fully quantitative. Nevertheless, even treated as approximation, they allow rationalizing experimental observations, for example lack of high-energy conformers VII and VIII.

In the discussion below, data obtained in argon and xenon matrixes will be considered in deeper detail, since observations made in krypton matrixes were essentially similar to those made in xenon. Discussion will be focused only into two spectral regions, the carbonyl stretchings region $\left(1660-1780 \mathrm{~cm}^{-1}\right)$ and the $1200-1280 \mathrm{~cm}^{-1}$ range, because in these two regions the general spectral profiles and their changes with both temperature and matrix gas are more clear. However, it shall be noticed that the conclusions presented below are also supported by the detailed analysis of other spectral regions.

1. 1660-1780 $\mathrm{cm}^{-1}$ Region ( $C=O$ Stretching Vibrations). In the carbonyl region of the PTD spectrum in solid argon (asdeposited matrix) there are bands in two spectral ranges: around $1750 \mathrm{~cm}^{-1}$ and $1700-1740 \mathrm{~cm}^{-1}$. Absolute maxima in these two spectral ranges are observed at 1751 and $1713 \mathrm{~cm}^{-1}$, respectively. Clearly, each spectral region is formed by several overlapping bands, this being particularly noticeable in the case of the low frequency region (Figure 4a). In xenon (Figure 4b), the band structure in the low frequency region is more evident and relative maxima can be easily noticed at 1719, 1711, 1706, and $1703 \mathrm{~cm}^{-1}$. Additionally, a low-intensity shoulder at 1695 $\mathrm{cm}^{-1}$ is present. The higher frequency region has the absolute maximum at $1746 \mathrm{~cm}^{-1}$.

The calculations predict two absorptions in this region for each conformer, giving rise, as a whole, to three bands centered at 1765,1734 , and $1721 \mathrm{~cm}^{-1}$ in the summary spectrum (see Figure $4 \mathrm{c}$ ). The absorption predicted to occur at $1765 \mathrm{~cm}^{-1}$ is ascribed to the stretching vibrations of the $\mathrm{C}=\mathrm{O}$ groups in the trans conformation, i.e. in forms III, IV, V, and VI, and corresponds to the bands observed experimentally in the higher frequency region, at ca. $1751 \mathrm{~cm}^{-1}$ (in argon) and $1746 \mathrm{~cm}^{-1}$ (in xenon). The two other theoretically predicted bands (1734 and $1721 \mathrm{~cm}^{-1}$ ) correspond to the stretching vibrations of $\mathrm{C}=$ $\mathrm{O}$ groups in the cis arrangement. All conformers expected to be relevant experimentally $(\mathbf{I}-\mathbf{V I})$ have at least one $\mathrm{C}=\mathrm{O}$ group in this arrangement: forms I, II, III, and IV contribute to the predicted band at $1734 \mathrm{~cm}^{-1}$, while I, II, V, and VI contribute to that at $1721 \mathrm{~cm}^{-1}$. These two theoretically predicted bands relate with the bands observed in the $1700-1740 \mathrm{~cm}^{-1}$ region in the matrix spectra.

Annealing of the argon matrix (cf. Figure 5a) within the temperature range $11-27 \mathrm{~K}$ brings a slight decrease of intensity of the $1751 \mathrm{~cm}^{-1}$ band, with simultaneous general increase of the bands in the $1700-1740 \mathrm{~cm}^{-1}$ range. These changes could be due to conformational isomerization, therefore, and, to help in rationalizing the observations, the relevant conformational interconversion barriers were calculated (cf. Table 3 ). The pairs of conformers differing by one dihedral angle were considered only, as the barriers for these processes can be expected to be significantly lower than the barriers involving rotation about multiple bonds.

As shown in Table 3, the predicted barriers for conversion of conformer $\mathbf{V}$ into $\mathbf{I}$ and of conformer VI into II are quite small (4.6 and $2.9 \mathrm{~kJ} \mathrm{~mol}^{-1}$, respectively). According to the Barnes relationship, ${ }^{20}$ the rapid conversion of conformer $\mathbf{V}$ into conformer I can then be expected to take place in the matrix at temperatures in the range $20-30 \mathrm{~K}$, while conversion of conformer VI into II may require an even lower temperature. On the other hand, the barriers for conversion of forms III and IV into conformers II and I (ca. $10-11 \mathrm{~kJ} \mathrm{~mol}^{-1}$ ) are large enough to require a considerably higher temperature $\left(>40 \mathrm{~K}^{20}\right)$ to be overcome. These processes are then not expected to occur in the matrix. Therefore, the decrease of intensity of the band at $1751 \mathrm{~cm}^{-1}$ observed up to $27 \mathrm{~K}$ can be rationalized considering the conversion of conformers $\mathbf{V}$ and VI into the most stable forms I and II, respectively. [To exclude other possible abundance-affecting factors, irradiation of the argon matrix of the compound with the UV light (Xe lamp, Osram XBO $150 \mathrm{~W} / \mathrm{CR}$ OFR, $3 \mathrm{~h}$ ) was applied, demonstrating that the compound is photostable and the relative populations of the conformers do not change under influence of UV light.] As mentioned above, the decrease in intensity of the $1751 \mathrm{~cm}^{-1}$ band is accompanied by a general increase in the intensity of the absorptions in the $1700-1740 \mathrm{~cm}^{-1}$ spectral range, which have a predominant contribution from the $\mathrm{C}=\mathrm{O}$ stretches of conformers I and II.

These results are straightforward and are in consonance with both the relative stability of the various conformers predicted by the calculations and the calculated energy barriers for conformational interconversion. The more a priori unexpected 

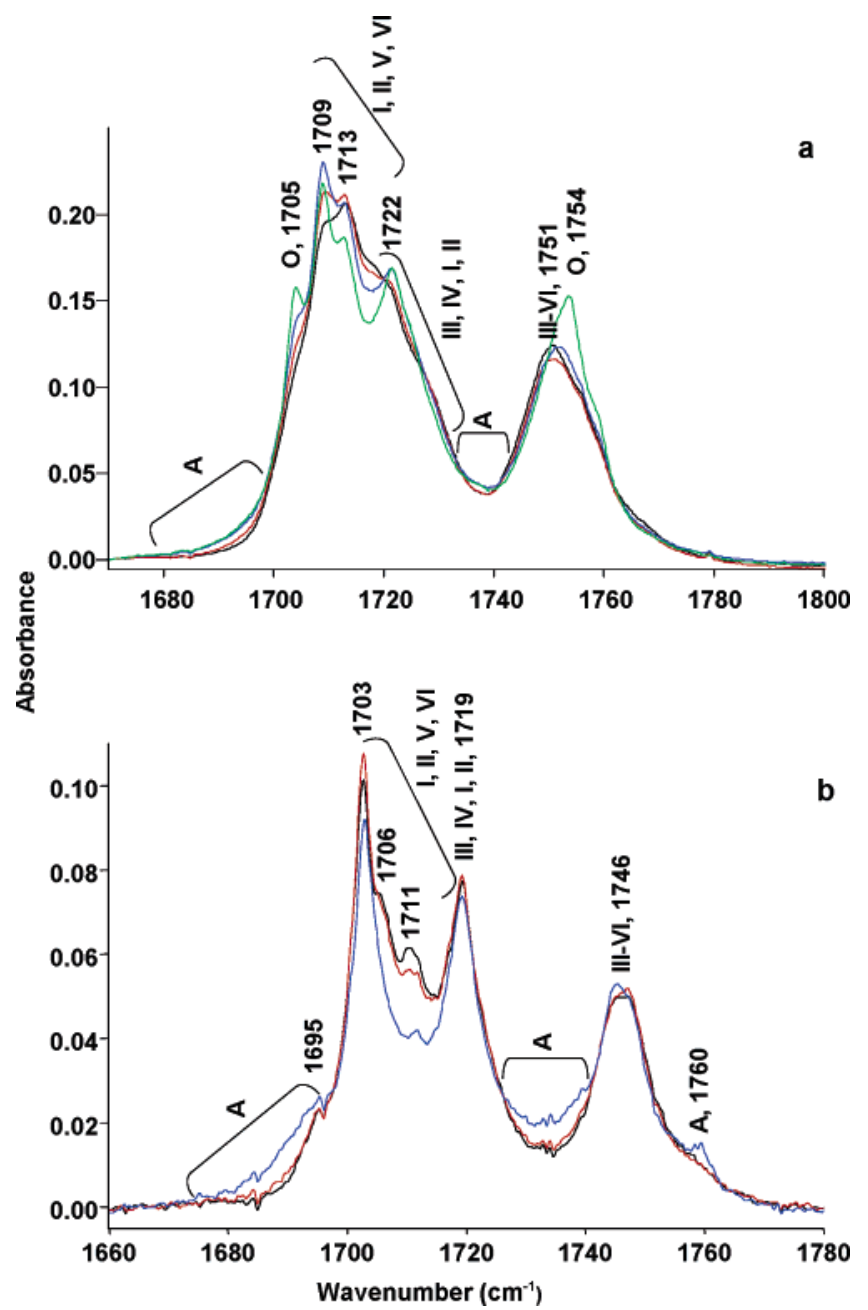

Figure 5. Carbonyl stretching vibrations spectral region of the IR spectra of matrix-isolated PTD: (a) isolated in argon matrix; (b) isolated in xenon matrix. Traces shown in panel a (argon) correspond to the spectra obtained immediately after deposition at $11 \mathrm{~K}$ (black), and after annealing to 23 (red), 27 (blue), and $31 \mathrm{~K}$ (green). Traces shown in panel (b) (xenon) correspond to the spectra obtained immediately after deposition at 20 (black), 36 (red), and $60 \mathrm{~K}$ (blue). "A" denotes highorder aggregates; "O" stands for transient long-range oligomers (see text).

results were obtained when the argon matrix of PTD was annealed to higher temperatures. Above $27 \mathrm{~K}$, two features, at 1754 and $1705 \mathrm{~cm}^{-1}$, grew considerably, whereas the intensity of all other bands in this range decreased (see Figure 5a). At first, these changes could be ascribed to aggregation, but the things cannot be so straightforward, since in the spectra of the neat compound in solid phase (both amorphous and crystalline) no bands are observed above $1725 \mathrm{~cm}^{-1}$ (spectra of neat PTD in the solid phases will be discussed later in this paper).

The observations can be explained as follows. At temperatures higher than ca. $27 \mathrm{~K}$, the argon matrix is much softer and some reorganization of the medium is expected. Therefore, the solute molecules are allowed to start approaching to each other and interact. Because of the size of PTD, however, the mobility of the molecules is low and the aggregation process is partially restricted. On the other hand, at a given point, when the solutesolute long-distance interactions between the approaching molecules start to become important, the electrostatic field felt by the interacting solute molecules changes and they may rearrange toward the conformer(s), which is (are) stabilized under these conditions. In the PTD case, the geometry of conformers $\mathbf{V}$ and/or VI seems to be close to intermediate
TABLE 3: Theoretical Values of Conformational Interconversion Barriers for Selected Conformers of PTD $\left(\mathbf{k J ~ m ^ { - 1 } ) ^ { a }}\right.$

\begin{tabular}{lcccccccc}
\hline & I & II & III & IV & V & VI & VII & VIII \\
\hline I & - & & 13.4 & & 8.6 & & & \\
II & & & 14.2 & & 9.3 & & & \\
& & & & 11.9 & & 7.1 & & \\
III & 10.7 & & - & 12.8 & & 7.8 & & \\
& 11.5 & & & & & & 8.7 & \\
IV & & 10.1 & & - & & & & 0.5 \\
V & 4.6 & 10.9 & & & & & & 1.3 \\
& 5.3 & & & & - & & 14.8 & \\
VI & & 2.9 & & & & - & & 12.1 \\
& & 3.6 & & & & & & 12.6 \\
VII & & & 1.4 & & 7.8 & & - & \\
VIII & & & 2.2 & & 8.3 & & & -
\end{tabular}

${ }^{a}$ Calculations done at B3LYP/6-31+G(p) level using the STQN method (QST3). Values given include the zero-point correction to energy. The conformers in rows and columns denote reactants and products, respectively. Two different values are given due to two different possible pathways.

configuration before aggregation, as it is shown by the observed growth of the band at $1754 \mathrm{~cm}^{-1}$, at nearly the same frequency of the monomeric band at $1751 \mathrm{~cm}^{-1}$ to which, as pointed out above, these conformers contribute. Note that conformers III and IV do also contribute to the band at $1751 \mathrm{~cm}^{-1}$. However, conformational reorganization to these forms before aggregation, induced by the increase of the electrostatic field due to approaching of the solute molecules during annealing, is rather improbable, since they have significantly lower dipole moments when compared to $\mathbf{V}$ and VI (among the six experimentally relevant conformers of PTD, III and IV are those having the lowest dipole moments; see Table 2). Moreover, the barriers for conversion of the most abundant conformers in the asdeposited matrix, I and II, into conformers $\mathbf{V}$ and VI, respectively, are significantly lower than those associated with the conversion of these forms into conformers III and IV (ca. 7-9 $\mathrm{kJ} \mathrm{mol}^{-1}$ vs ca. $12-14 \mathrm{~kJ} \mathrm{~mol}^{-1}$; see Table 3 ). The observation of the transient long-range oligomers is possible due to the restricted translational freedom of PTD molecules in the matrix. It is clearly noticeable in the argon matrix because in this case the initially dominant conformers (I and II) have geometries and vibrational signatures that differ considerably from that assumed by the monomeric units in the aggregated species. It is worth mentioning that such kind of intermediate structures was observed previously in a neon matrix in relation with the process of aggregation of $\mathrm{NO} .^{21}$

Very interestingly, the spectroscopic results point to a structure of the PTD molecules in the aggregates where the methyl ester groups are in a more planar conformation than in the isolated monomer. Indeed, due to the polarization of the $\mathrm{C}=\mathrm{C}-\mathrm{C}=\mathrm{O}$ moieties, where the positively and negatively charged atoms are alternate $\left(\mathrm{C}^{\delta-}=\mathrm{C}^{\delta+}-\mathrm{C}^{\delta+}=\mathrm{O}^{\delta-}\right)$, the throughspace field interaction between the dipoles associated with the $\mathrm{C}^{\delta-}=\mathrm{C}^{\delta+}$ and $\mathrm{C}^{\delta+}=\mathrm{O}^{\delta-}$ bonds leads to increase of the double bond character in the case of the trans $\mathrm{C}^{\delta-}=\mathrm{C}^{\delta+}-\mathrm{C}^{\delta+}=\mathrm{O}^{\delta-}$ conformation and to a decrease in it in the cis geometry. Naturally, these effects are more pronounced for more planar geometries, where the alignment (parallel for trans and antiparallel for cis) between the two bonds is more effective. Consequently, the carbonyl stretching frequency can be expected to increase for the trans and decrease for the cis arrangement, 
when the corresponding methyl ester group approaches more to the plane of the rings. This is exactly what is observed experimentally, with the frequency associated with the trans methyl ester group increasing from 1751 to $1754 \mathrm{~cm}^{-1}$ and that associated with the cis methyl ester group decreasing from around $1709-1713 \mathrm{~cm}^{-1}$ to $1705 \mathrm{~cm}^{-1}$.

It is also worth mentioning that conventional short-range higher order aggregates of PTD were also present in some extent in the annealed argon matrix, as revealed by the observation of the broad shoulder in the $1680-1700 \mathrm{~cm}^{-1}$ region, which increases in intensity during annealing.

The results obtained in xenon matrixes provided further information to understand the conformational behavior of PTD. As already mentioned, in this case the spectrum of the as-deposited matrix $(20 \mathrm{~K})$ exhibits a set of superimposed absorptions in the $1700-1740 \mathrm{~cm}^{-1}$ region (with relative maxima at $1719,1711,1706$, and $1703 \mathrm{~cm}^{-1}$ ), which correlate with the broad structured band observed in argon nearly in the same spectral region, and a higher frequency band, due to conformers III-VI, with maximum at $1746 \mathrm{~cm}^{-1}\left(1751 \mathrm{~cm}^{-1}\right.$ in argon). Noteworthy, the profile in the $1700-1740 \mathrm{~cm}^{-1}$ region observed in the as-deposited xenon matrix (Figure $5 \mathrm{~b}$ ) resembles closely that corresponding to the argon matrix after annealing to $31 \mathrm{~K}$, though the bands show the usual frequency shifts to lower values (e.g., the bands observed in argon at 1720 and $1709 \mathrm{~cm}^{-1}$ correlate respectively with the bands at 1719 and $1703 \mathrm{~cm}^{-1}$ in xenon). On the other hand, when compared with the spectrum of the as-deposited argon matrix, the spectrum obtained in xenon shows a substantial reduction of intensity in the region between 1703 and $1719 \mathrm{~cm}^{-1}$ (corresponding to the region between 1709 and $1720 \mathrm{~cm}^{-1}$ observed in argon). This observation can be correlated with a comparatively smaller amount of conformers $\mathbf{I}$ and II in the as-deposited xenon matrix. Since the temperatures of the vapor of PTD before deposition were close enough in the two series of experiments (argon and xenon) to keep relative populations of the conformers nearly unchanged (see Table 2), the notoriously different trapped conformational populations imply the occurrence of conformational cooling during deposition of the xenon matrix. It is wellknown that xenon is a much better matrix-gas to induce conformational cooling than argon. ${ }^{22-23}$ Since conformational cooling must necessarily lead to increase of the population of the conformers that are more stable in the matrix, the experimental data indicate that in the xenon matrixes (and also in the krypton ones) the relative stability of forms I/II and V/VI are reversed compared to both gas-phase and argon matrixes. There are other molecular systems where similar observations were reported; i.e., the most polar forms were found to be stabilized in the more polarizable matrixes and became more stable than the (less polar) forms that are the most stable ones in the gasphase or less polarizable matrixes. ${ }^{22-23}$ The necessary general conditions that need to be satisfied to make possible experimental observation of this inversion of the relative stability of conformers are (i) close energies of the conformers in the gas phase (with the less polar form being the most stable), (ii) significant differences in the dipole moments of the conformers, and (iii) accessible energy barriers for conformational isomerization. All these conditions are fulfilled in the case of the relevant conformers of PTD (forms I/II and V/VI).

In consonance with the reversed order of stability of conformers I/II and V/VI in the xenon matrix, the first stages of annealing of this matrix led to a small increase in the intensity of the bands at 1746 and $1703 \mathrm{~cm}^{-1}$, both of them expected to possess a significant contribution from forms $\mathbf{V}$ and $\mathbf{V I}$ (see
Figure 5b). Note that the $1703 \mathrm{~cm}^{-1}$ band must have contributions from $\mathbf{V}$ and VI, but also from $\mathbf{I}$ and II, as shown by the calculations (see Table 3S). However, in the xenon matrix, the $1703 \mathrm{~cm}^{-1}$ band has a dominant contribution from forms $\mathbf{V}$ and VI, which are the most abundant conformers in this matrix, while its counterpart in the spectrum obtained in argon (1709 $\mathrm{cm}^{-1}$ ) have a dominant contribution from I and II, since these forms are the most populated conformers in that matrix. Unless the two types of conformers would absorb exactly at the same position, the peak positions of the observed bands $\left(1709 \mathrm{~cm}^{-1}\right.$ in argon or $1703 \mathrm{~cm}^{-1}$ in xenon) are mainly determined by the population of the dominant forms and their peak intensity changes are determined by the change in the population of these forms. Consequently, during the first stages of annealing both bands increase slightly in intensity, since in each matrix the dominant conformers correspond to the most stable forms in that media and are then populated as a result of the conformational isomerization processes. Concomitantly, the bands mainly due to the corresponding less stable forms decrease of intensity (in argon, the band at $1751 \mathrm{~cm}^{-1}$, with important contributions from $\mathbf{V}$ and $\mathbf{V I}$, and in xenon the bands in the region between the 1703 and $1719 \mathrm{~cm}^{-1}$, which have important contributions from I and II; see Figure 5).

The changes upon annealing of the xenon matrix at higher temperatures (ca. $35 \mathrm{~K}$ ) were found to be less prominent than in argon matrix, because extensive conversion of conformers I and II into forms $\mathbf{V}$ and VI had already taken place during deposition of the matrix and in the first stages of annealing. Therefore, the spectra obtained at the highest temperatures during annealing reveal essentially the formation of high-order aggregates. When compared with the argon matrixes, the formation of these aggregates in the xenon matrixes is significantly facilitated by the a priori much larger population of the conformers that have the appropriate geometry to aggregate $(\mathbf{V}$ and VI). In fact, the shoulder observed at $1695 \mathrm{~cm}^{-1}$ (and also the weak broad band observed at $1760 \mathrm{~cm}^{-1}$ and that underlying between 1730 and $1740 \mathrm{~cm}^{-1}$ ), which is unequivocally ascribable to high-order aggregates, is observed from the very beginning in the spectra obtained in xenon (and similarly in krypton). This clearly indicates that formation of these species is facilitated in this media and may be formed during deposition, even when the guest-to-host ratio was lowered to a value significantly smaller than that used in experiments with argon as host gas. [In our experimental set up, the guest-to-host ratio cannot be determined precisely. However, relative guest-to-host ratios can be easily estimated from spectra, once the matrix gas fluxes and deposition times are equal, as in the present studies. The relative concentration of the matrixes in this case is directly proportional to the amount of PTD deposited and can be monitored by the absorbance values of the spectra of the compound. For example, in the case of the spectra shown in Figure 5, the concentration of the argon matrix is nearly twice that of the xenon matrix.]

2. $1200-1280 \mathrm{~cm}^{-1}$ Region. In the $1200-1280 \mathrm{~cm}^{-1}$ region the spectrum of PTD isolated in argon matrix shows bands at 1206, 1216, 1223, 1237, and $1247 \mathrm{~cm}^{-1}$ (cf. Figure 6a). In a xenon matrix, bands at 1206, 1216, 1234, 1242, and $1249 \mathrm{~cm}^{-1}$ are observed (cf. Figure 6b). According to the calculations, the bands at 1206 and $1247 \mathrm{~cm}^{-1}$ observed in argon and their counterparts in the spectra obtained in xenon $\left(1206 \mathrm{~cm}^{-1}\right.$ and site-split doublet at $1242 / 1249 \mathrm{~cm}^{-1}$ ) must result from superimposed absorptions of all the experimentally relevant conformers. On the other hand, the calculations predicted that forms I and II (cis/cis) should give rise to a well-separated band near 

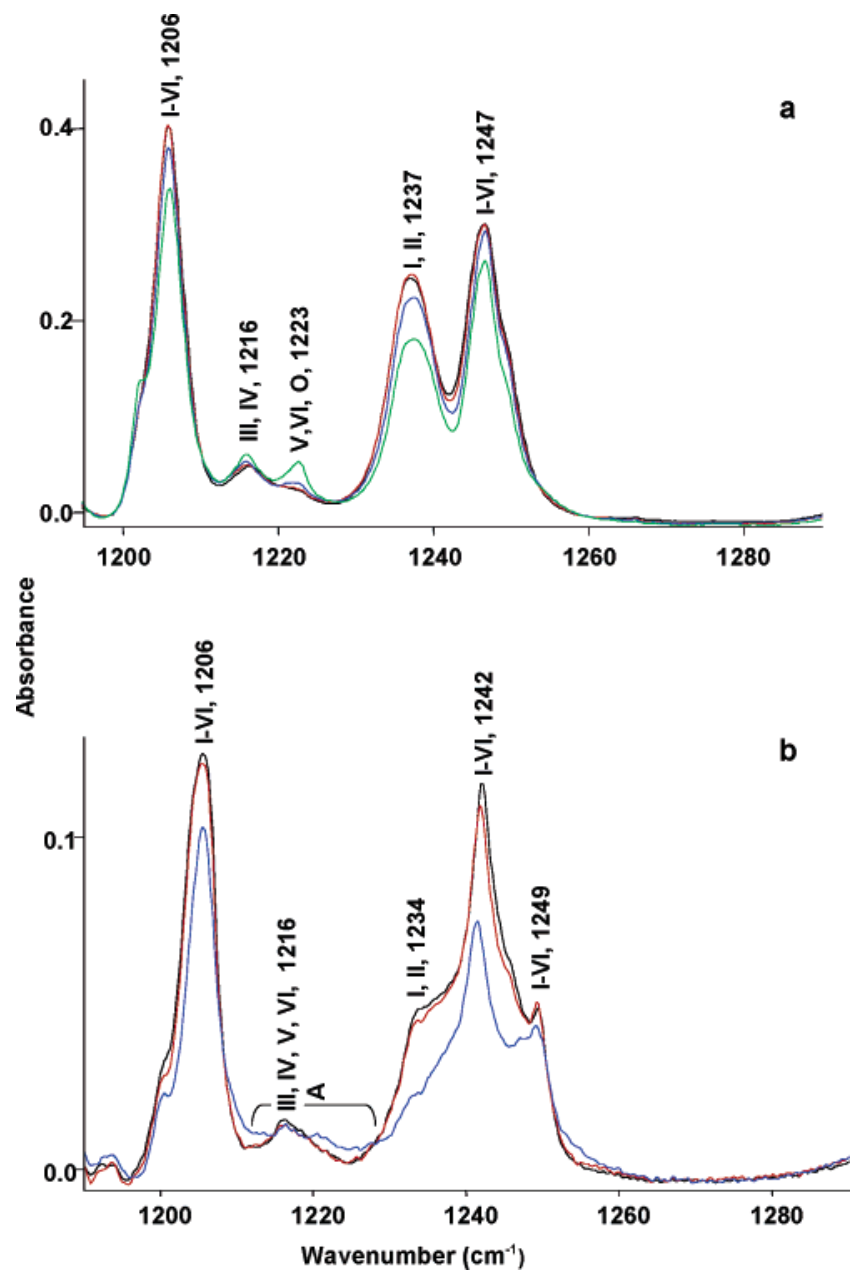

Figure 6. $1200-1280 \mathrm{~cm}^{-1}$ spectral region of the IR spectra of matrixisolated PTD: (a) isolated in argon matrix; (b) isolated in xenon matrix. Traces shown in panel (a) (argon) correspond to the spectra obtained immediately after deposition at $11 \mathrm{~K}$ (black), and after annealing to 23 (red), 27 (blue), and $31 \mathrm{~K}$ (green). Traces shown in panel b (xenon) correspond to the spectra obtained immediately after deposition at 20 (black), 36 (red), and $60 \mathrm{~K}$ (blue). "A" denotes high-order aggregates; "O" stands for transient long-range oligomers (see text).

$1235 \mathrm{~cm}^{-1}$ (calculated values: $1236,1235 \mathrm{~cm}^{-1}-\mathbf{I}$, II; mostly a methyl rocking vibration-see Tables $2 \mathrm{~S}$ and $3 \mathrm{~S}$ ). The four trans/cis conformers should absorb at lower frequencies (calculated values: $1218,1217,1216$, and $1216 \mathrm{~cm}^{-1}$, for IV, III, $\mathbf{V}$, and VI, respectively).

The band at $1237 \mathrm{~cm}^{-1}$ in argon could then be easily assigned to conformers I and II. This band showed the expected behavior upon annealing, starting to decrease only at temperatures higher than $27 \mathrm{~K}$. The most significant indication on the origin of this band is, however, the much lower intensity of its counterpart band in the case of xenon matrix (at $1234 \mathrm{~cm}^{-1}$ ), which is consistent with the conversion of these forms into conformers $\mathbf{V}$ and VI during deposition of this latter matrix, and then with the conclusions previously extracted based on the analysis of the carbonyl stretching region.

The bands at 1223 and $1216 \mathrm{~cm}^{-1}$ in argon, which experience distinct patterns of variation of intensity with annealing, are ascribed to conformers V/VI, and III, and IV, respectively. As expected, the band due to forms III and IV is practically unaffected by annealing. On the other hand, the band due to conformers $\mathbf{V}$ and VI systematically increases in intensity. With all probability, this band results from both monomeric species and transient long-range oligomers. In fact, its pattern of variation with temperature is identical to that followed by the

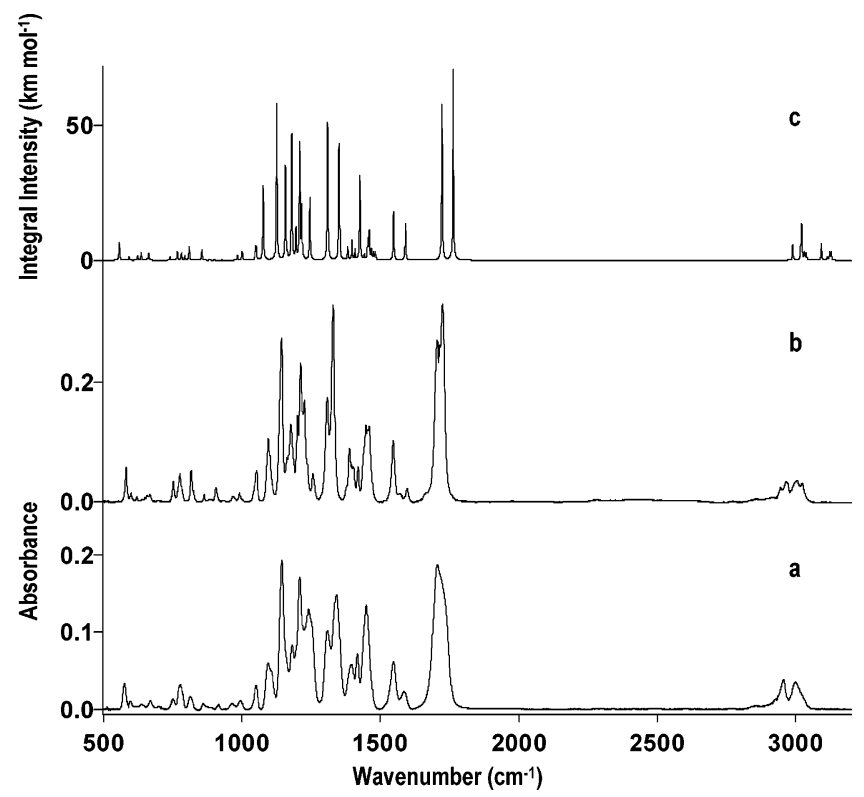

Figure 7. Comparison of FT-IR spectra of the amorphous (a) and crystalline (b) phases of PTD with the calculated spectrum of conformer VI (c).

bands at 1705 and $1754 \mathrm{~cm}^{-1}$ observed in the carbonyl stretching region and ascribed above to this latter species. In xenon, only one broad band at ca. $1216 \mathrm{~cm}^{-1}$ is noticed, resulting from overlap of bands due to conformers III, IV, V, and VI. Annealing brings an increase of the intensity in this spectral region, which is due to the absorption of aggregates. As it could be expected considering the relevance of conformers V/VI to the structure of the aggregates, this gain of intensity was found to be particularly noticeable in the higher frequency wing of the $1216 \mathrm{~cm}^{-1}$ band.

4.3. Amorphous Solid and Crystalline State of PTD. The observed stabilization of conformers $\mathbf{V} / \mathbf{V I}$ in the xenon (and krypton) matrixes, as well as the observed increase of the population of at least one of these conformers during annealing of the argon matrix, giving rise to the transient long-range oligomers described in the previous section, suggested the dominance of this species in the neat solid state of the compound. Therefore, a solid amorphous film of PTD was obtained from fast deposition of the vapor of the substance (at $423 \mathrm{~K}$ ) onto the cold tip of the cryostat kept at $11 \mathrm{~K}$, and subsequently annealed up to the temperature (ca. $298 \mathrm{~K}$ ) at which the transition of amorphous to crystalline state was noticed. The spectra of both the as-deposited amorphous and crystalline solids of PTD are presented in Figure 7.

Although the bands are considerably broadened in the amorphous phase spectrum (Figure 7a), the frequencies of the absorptions are nearly coincident with the frequencies observed in the matrix spectra. This can be easily correlated with the fact that PTD is not able to form strong intermolecular H-bonds due to the lack of efficient proton donor groups. Therefore, stacking between the pyrrole rings is probably the dominating type of intermolecular interactions in the neat amorphous state (this is also in agreement with the indication provided from the spectroscopic data for the matrix isolated PTD that the methyl ester groups in the aggregates approach the plane of the rings; the molecule as a whole becomes more planar, then allowing for better stacking). Nevertheless, the observed shift of the band assigned to the $\mathrm{S}=\mathrm{O}$ stretching vibration from ca. $1367 \mathrm{~cm}^{-1}$ in the matrixes to ca. $1342 \mathrm{~cm}^{-1}$ in the amorphous phase (to ca. $1329 \mathrm{~cm}^{-1}$ in the case of the crystalline state) may be an 
indication that in the neat solid this group is involved in a weak H-bond, possibly with one of the methylene ring or methyl ester groups acting as a donor. The existence of such kind of interaction must, however, not be taken as established, since the observed frequency shift, though being considerable, can just be due to a change of polarity of the media.

Compared with the spectrum of the amorphous film, the spectrum of the crystal (Figure $7 \mathrm{~b}$ ) presents bands considerably narrower. This could be anticipated taking into consideration the greater similarity of the local molecular environment in the ordered crystalline state, comparatively to the unordered amorphous phase. However, the peak positions in both spectra do not differ very much, and the number of observed bands does not change appreciably (when new bands are apparent in the crystalline state spectrum, they result from the better intrinsic resolution of this spectrum compared to that of the amorphous phase, while no bands observed in this latter disappear after crystallization). These results point to the presence in both the amorphous phase and crystal of the same molecular species. Taking into consideration the results obtained for the matrix isolated compound, either conformer $\mathbf{V}$ or $\mathbf{V I}$ are good candidates for being such species (or a mixture of both forms). Indeed, as already mentioned, the IR signature of these two forms are so identical that they cannot be distinguished even in the case of the matrix isolated compound. [In Figure 7c we present also the calculated spectrum for conformer VI-the most polar form; as can be seen, it fits nicely the experimental spectra of both neat amorphous phase and crystal of PTD; the same happens with the spectrum of conformer $\mathbf{V}$, that is, in practical terms, indistinguishable from that of form VI.] Thus, the precise determination of the form(s) present in the neat condensed phases must be undertaken by using another technique, such as $\mathrm{X}$-ray or neutron diffraction.

A final comment should be done regarding the possibility of presence of other conformers than V/VI in the neat solid phases. Taking into account the changes in the relative amounts of conformers $\mathbf{I} / \mathbf{I I}$ and $\mathbf{V} / \mathbf{V I}$ upon changing from the argon to xenon matrixes, the presence of conformers I and II in the neat condensed phases look very improbable. On the other hand, the calculated gas-phase barriers associated with conversion of conformers III and IV into other forms are somewhat higher than those for interconversion between forms I/II and V/VI (see Table 3). However, also in this case at least the III $\rightarrow$ I and IV $\rightarrow$ II barriers are well within the range of values (ca. $10 \mathrm{~kJ}$ $\mathrm{mol}^{-1}$ ) which allow to admit that, once the effect of the media is taken into account, they can be overcome during preparation of the solid film of the compound from the vapor phase. Note that forms III and IV have the lowest dipole moment among all conformers and they shall be considerably destabilized in the neat amorphous phase relative to the gas-phase. This fact leads necessarily to lower energy barriers for isomerization of these conformers in the solid. Hence, the presence of conformers III and IV in the amorphous phase looks very improbable. Under this assumption, its presence in the crystal can also be ruled out, by absence of dramatic spectral changes upon crystallization.

\section{Conclusions}

The structural analysis of dimethyl 5-methyl- $1 H, 3 H$-pyrrolo[1,2-c][1,3]thiazole-6,7-dicarboxylate 2,2-dioxide (PTD) was performed in low-temperature argon, krypton, and xenon matrixes, as well as in the neat amorphous and crystalline phases, using infrared spectroscopy and DFT calculations.

On the basis of the DFT calculations, six conformers with three different arrangements (cis/cis, trans/cis, and cis/trans) of the $\mathrm{C}_{2} \mathrm{C}_{1} \mathrm{C}_{19} \mathrm{O}_{21}$ and $\mathrm{C}_{5} \mathrm{C}_{4} \mathrm{C}_{20} \mathrm{O}_{23}$ groups relative to the ring system of the molecule were predicted to exist in the gas phase equilibrium with experimentally significant populations within the temperature range $388-423 \mathrm{~K}$. In consonance with the theoretical predictions, the subtle differences in the vibrational spectra of the conformers belonging to the same group prevented any identification of individual conformers within a group. Nevertheless, the presence of these three groups of conformers was undoubtedly confirmed in the matrixes. The conformers with both $\mathrm{C}_{2} \mathrm{C}_{1} \mathrm{C}_{19} \mathrm{O}_{21}$ and $\mathrm{C}_{5} \mathrm{C}_{4} \mathrm{C}_{20} \mathrm{O}_{23}$ dihedral angles in pseudo cis arrangement (I and II) are most stable in both the gas phase and argon matrix. The higher polarizability of the krypton and, particularly, xenon matrix results in change of the order of stability of the conformers of PTD in these media: the conformers with the highest dipole moment (trans/cis; $\mathbf{V}$ and VI) become the most stable forms, as it is demonstrated by the comparison of the as-deposited spectra obtained for matrixes of different hosts as well as by annealing experiments.

In argon matrixes, transient long-range oligomers were observed, whose constituting units are similar to forms V/VI, though presenting a slightly higher degree of planarity than the isolated monomers. In the more polarizable $\mathrm{Kr}$ and $\mathrm{Xe}$ matrixes, forms $\mathbf{V} / \mathbf{V I}$ are dominant even in the as-deposited matrix, due to conformational cooling during deposition (conversion of $\mathbf{I} / \mathbf{I I}$ into the most stable in these media conformers V/VI). In the neat solid compound (both amorphous and crystal), only forms V and VI (or one of these) exist.

Acknowledgment. Calculations were done at the Academic Computer Center "Cyfronet", Krakow, Poland (Grant KBN/ SGI_ORIGIN_2000/UJ/044/1999) and The Interdisciplinary Center for Mathematical and Computational Modeling, Warsaw University, Warsaw, Poland, which are acknowledged for computing time. The research was supported by the Portuguese Fundação para a Ciência e a Tecnologia (Grant FCT \#SFRH/ BPD/17081/2004 and Project POCI/QUI/59019/2004, also supported by FEDER).

Supporting Information Available: Table 1S, geometry of PTD conformers calculated at B3LYP/6-311++G(d,p) level, Table 2S, definition of internal coordinates used in the normalmode analysis of PTD, Table 3S, assignment of experimental spectra of PTD in $\mathrm{Ar}$ and Xe matrixes at 11 and $20 \mathrm{~K}$, respectively, and Table $4 \mathrm{~S}$, IR frequencies observed in the spectra of amorphous and crystalline state of PTD with the assignment of the crystalline state based on calculated frequencies of conformer VI. This material is available free of charge via the Internet at http://pubs.acs.org.

\section{References and Notes}

(1) Anderson, W. K.; Mach, R. H. J. Med. Chem. 1987, 30, 2109.

(2) Ladureé, D.; Lancelot, J.-C.; Robba, M.; Chenu, E.; Mathé, G. J. Med. Chem. 1989, 32, 456.

(3) Lavé, D.; James, C.; Rajoharison, H.; Bost, P. E.; Cavero, I. Drugs Future 1989, 14, 891.

(4) Davidsen, S. K.; Summers, J. B.; Albert, D. H.; Holms, J. H.; Heyman, H. R.; Magoc, T. J.; Conway, R. G.; Rhein, D. A.; Carter, G. W. J. Med. Chem. 1994, 37, 4423.

(5) Sutcliffe, O. B.; Storr, R. C.; Gilchrist, T. L.; Rafferty, P. J. Chem. Soc., Perkin Trans. 1 2001, 1795.

(6) Pinho e Melo, T. M. V. D.; Soares, M. I. L.; d'A. Rocha Gonsalves, A. M.; Paixão, J. A.; Matos Beja, A.; Ramos Silva, M. J. Org. Chem. 2005, $70,6629$.

(7) Kane, J. M. J. Org. Chem. 1980, 45, 5396.

(8) Sutcliffe, O. B.; Storr, R. C.; Gilchrist, T. L.; Rafferty, P. Tetrahedron 2000, 56, 10011.

(9) Padwa, A.; Fryxell, G. E.; Gasdaska, J. R.; Venkatramanan, M. K.; Wong, G. S. K. J. Org. Chem. 1989, 54, 644. 
(10) Becke, A. D. Phys. Rev. A 1988, 38, 3098.

(11) Lee, C. T.; Yang, W. T.; Parr, R. G. Phys. Rev. B 1988, 37, 785.

(12) Borba, A.; Gómez-Zavaglia, A.; Simões, P. N. N. L.; Fausto, R. Spectrochim. Acta A 2005, 61, 1461.

(13) Borba, A.; Gómez-Zavaglia, A.; Simões, P. N. N. L.; Fausto, R. J. Phys. Chem. A 2005, 109, 3578.

(14) Zeng, A.; Yu, L.; Wang, Y.; Kong, Q.; Xu, Q.; Zhou, M. J. Phys. Chem. A 2004, 108, 6656.

(15) Peng, C.; Schlegel, H. B. Isr. J. Chem. 1994, 33, 449.

(16) Frisch, M. J.; Trucks, G. W.; Schlegel, H. B.; Scuseria, G. E.; Robb, M. A.; Cheeseman, J. R.; Montgomery, J. A., Jr.; Vreven, T.; Kudin, K. N.; Burant, J. C.; Millam, J. M.; Iyengar, S. S.; Tomasi, J.; Barone, V.; Mennucci, B.; Cossi, M.; Scalmani, G.; Rega, N.; Petersson, G. A.; Nakatsuji, H.; Hada, M.; Ehara, M.; Toyota, K.; Fukuda, R.; Hasegawa, J.; Ishida, M.; Nakajima, T.; Honda, Y.; Kitao, O.; Nakai, H.; Klene, M.; Li, X.; Knox, J. E.; Hratchian, H. P.; Cross, J. B.; Adamo, C.; Jaramillo, J.; Gomperts, R.; Stratmann, R. E.; Yazyev, O.; Austin, A. J.; Cammi, R.; Pomelli, C.; Ochterski, J. W.; Ayala, P. Y.; Morokuma, K.; Voth, G. A.; Salvador, P.; Dannenberg, J. J.; ZaXezewski, V. G.; Dapprich, S.; Daniels, A. D.; Strain, M. C.; Farkas, O.; Malick, D. K.; Rabuck, A. D.;
Raghavachari, K.; Foresman, J. B.; Ortiz, J. V.; Cui, Q.; Baboul, A. G.; Clifford, S.; Cioslowski, J.; Stefanov, B. B.; Liu, G.; Liashenko, A.; Piskorz, P.; Komaromi, I.; Martin, R. L.; Fox, D. J.; Keith, T.; Al-Laham, M. A.; Peng, C. Y.; Nanayakkara, A.; Challacombe, M.; Gill, P. M. W.; Johnson, B.; Chen, W.; Wong, M. W.; Gonzalez, C.; Pople, J. A. Gaussian 03, revision C.02; Gaussian, Inc.: Wallingford CT, 2004.

(17) Pulay, P.; Fogarasi, G.; Pang, F.; Boggs, J. E. J. Am. Chem. Soc. 1979, 101,2550 .

(18) Martin, J. M. L.; Van Alsenoy, C. Gar2ped; University of Antwerp: Antwerp, Belgium, 1995.

(19) El-Gogary, T. M.; Soliman, M. S. Spectrochim. Acta A 2001, 57, 2647.

(20) Barnes, A. J. J. Mol. Struct. 1984, 113, 161.

(21) Kometer, R.; Legay, F.; Legay-Sommaire, N.; Schwentner, N. J. Chem. Phys. 1994, 100, 8737.

(22) Reva, I. D.; Stepanian, S. G.; Adamowicz, L.; Fausto, R. Chem. Phys. Lett. 2003, 374, 631.

(23) Gómez-Zavaglia, A.; Fausto, R. Phys. Chem. Chem. Phys. 2003 